\title{
Discussão sobre gênero nas escolas Ações e resistências
}

\author{
Gender Discussion at Schools
}

Actions and resistance

\section{Discusión sobre género en las escuelas}

Acciones y resistencias

ELIANE ROSE MAIO*

Universidade Estadual de Maringá, Maringá - PR, Brasil.

MÁRCIO DE OLIVEIRA**

Universidade Federal do Amazonas, Manaus - AM, Brasil.

REGINALDO PEIXOTO***

Universidade Estadual do Mato Grosso do Sul, Paranaíba - MS, Brasil.

RESUMO: As discussões relacionadas a gênero devem ser frequentes nas práticas escolares, sobretudo pelo fato de a escola contribuir na formação de seus/suas alunos/as por um longo período de tempo. O presente manuscrito tem como objetivo geral traçar um panorama sobre as questões de gênero em alguns documentos oficiais brasileiros e apresentar propostas de práticas escolares envolvendo o tema. Utilizamos de pesquisas bibliográficas e documentais, de caráter exploratório e qualitativo. É possível concluir que há, ainda, um pânico moral que perpetua nos espaços escolares, para se trabalhar com esta

* É graduada em Psicologia pela Universidade Estadual de Maringá. Mestra em Psicologia pela Universidade Estadual Paulista (UNESP/Assis). Doutora e Pós-doutora em Educação Escolar (UNESP/Araraquara). Atualmente é professora na Universidade Estadual de Maringá e líder do grupo de pesquisa CNPq, intitulado Núcleo de Pesquisa e Estudo em Diversidade Sexual (NUDISEX). E-mail: <elianerosemaio@yahoo.com.br>.

** É graduado em Pedagogia, pela Universidade Estadual de Maringá, Mestre e Doutor em Educação pela Universidade Estadual de Maringá. É Professor na Universidade Federal do Amazonas (Campus Manaus) e integrante do grupo de estudos NUDISEX.E-mail: <marcio.1808@hotmail.com>.

*** É graduado em Letras (Português), Arte e Educação e Pedagogia. Mestre em Educação pela Universidade Estadual de Maringá e Doutor em Educação, Arte e História da Cultura pela Universidade Presbiteriana Mackenzie. Atualmente é professor na Universidade Estadual de Mato Grosso do Sul (Unidade Paranaíba). E-mail:<regi.peixoto77@gmail.com>. 
temática, apesar de ter materiais, científicos, suficientes para atuar nas instituições.

Palavras-chave: Gênero. Documentos oficiais. Práticas escolares.

\begin{abstract}
Discussions related to gender ought to be frequent in school practices, mainly due to the fact of schools contributing to students' nurturing over a long period of time. The overall objective of this manuscript is to provide an overview of gender issues via some official Brazilian documents and to introduce proposals for school practices involving the theme. We have used exploratory and qualitative sources for bibliographical and documentary research. It is possible to conclude that, there is, still, a moral-fright, which perpetuates in school areas when working on this theme, despite the fact that there is enough scientific - and nonscientific - material in order to act in the institutions.
\end{abstract}

Keywords: Gender. Official documents. School practices.

RESUMEN: Las discusiones relacionadas con el género deben ser frecuentes en las prácticas escolares, especialmente porque la escuela contribuye a la formación de sus estudiantes por un largo período. El objetivo general de este manuscrito es proporcionar una visión general de las cuestiones de género en algunos documentos oficiales brasileños y presentar propuestas de prácticas escolares relacionadas con el tema. Utilizamos investigación bibliográfica y documental, exploratoria y cualitativa. Es posible concluir que todavía existe un pánico moral que se perpetúa en los espacios escolares para trabajar con este tema, a pesar de haber suficientes materiales científicos para actuación en las instituciones.

Palabras clave: Género. Documentos oficiales. Prácticas escolares.

\title{
Introdução
}

O importante não é que nós saibamos do texto o que nós pensamos do texto, mas o que-com o texto, ou contra o texto ou a partir do textonós sejamos capazes de pensar (LARROSA, 2010, p. 142). 

sta citação nos instiga a refletir como as temáticas de gênero e sexualidade estão - ou não - sendo inseridas nos espaços escolares. A partir dos documentos oficiais e das políticas públicas, é sabido que há a possibilidade de discutir tais temas na educação. Mas, será que essa discussão ocorre?

Dessa forma, temos como objetivo geral neste artigo traçar um panorama sobre as questões de gênero em alguns documentos oficiais brasileiros e apresentar propostas de práticas escolares envolvendo o tema. E, para atingir o objetivo, realizamos pesquisas bibliográficas e documentais, de cunho exploratório e qualitativo.

Há muitos/as autores/as nacionais e internacionais que discutiram e discutem a categoria gênero (BUTLER, 2015; MEYER, 2010; LOURO, 2001; OLIVEIRA, 2017). No entanto, mesmo com o vasto material acadêmico e científico já produzido, esse termo ainda é considerado um tabu social, além de ser interpretado - muitas vezes - de forma errônea e/ou simplista, incluindo por profissionais da área da educação (foco no decorrer desse manuscrito).

Dagmar Meyer (2010, p. 16) enfatiza que gênero aponta para a noção de que, ao longo da vida, por meio "[...] das mais diversas instituições e práticas sociais, nos constituímos como homens e mulheres, num processo que não é linear, progressivo ou harmônico e que também nunca está finalizado ou completo". Assim, fica evidente que as diversas instituições às quais nos relacionamos contribuem para a formação/construção de gênero, de maneira positiva ou negativa.

A partir desse cenário, nos debruçamos em apresentar alguns apontamentos sobre concepções de gênero, em um primeiro momento; após apresentamos alguns documentos oficiais brasileiros que anunciam proposições para se atuar com estes temas nas escolas; e terminamos com propostas de atuações, apesar de tantos retrocessos e pânico moral estabelecidos pelas ações conservadoras brasileiras.

\section{Gênero: notas necessárias}

No Brasil, a categoria gênero ganha uma nova roupagem - um certo pânico moral - sobretudo a partir de 2014, quando das discussões e da formulação do Plano Nacional de Educação (PNE) (BRASIL, 2014a). Naquele momento, grupos conservadores ligados a várias denominações religiosas pressionaram o poder público a fim de retirar do documento a palavra gênero (e seus desdobramentos). E assim foi feito! Esse cenário foi constituído, sobretudo, a partir da chamada "ideologia de gênero" que acabou por dar ênfase - ainda maior - na oposição entre os grupos progressistas e conservadores; e esse último passou, incansavelmente, a trabalhar para barrar projetos de lei que almejavam avanços em áreas sociais e culturais, a exemplo da educação. 
Elaine Brandão e Rebecca Lopes (2018, p. 107) explicam - com detalhes - o processo relacionado a esse ataque à educação pública quando - usando sítios eletrônicos - mencionam os discursos contra a manutenção de aspectos relacionados a gênero no PNE. De acordo com as autoras, são vários os documentos que mencionam "[...] a "bancada cristã", a "cruzada religiosa", o "lobby religioso" ou o "lobby conservador" ao designarem as forças políticas de oposição à inclusão das temáticas relativas à defesa e afirmação dos direitos humanos nos documentos oficiais".

As autoras ainda ressalvam que esse grupo conservador reúne parlamentares de diversos partidos políticos, a exemplo do Partido Social Democracia Brasileira (PSDB), Movimento Democrático Brasileiro (MDB), Social Cristão (PSC), incluindo parlamentares à época como Marcos Feliciano (PSC-SP), Jair Bolsonaro (PSC-RJ), Pastor Eurico (PHS-PE), Eduardo Cunha (PMDB-RJ), entre outros/as (BRANDÃO; LOPES, 2018).

A palavra gênero e orientação sexual, assim, não aparecem no PNE. Vale ressaltar que o Projeto de Lei no 103/2012 que tramitava para aprovação na Câmara dos/as Deputados/as mencionava a inclusão de categorias sociais em seu texto logo no início do documento, a saber: no artigo segundo, inciso III, terceira diretriz, em que se lia: “[...] superação das desigualdades educacionais, com ênfase na promoção da igualdade racial, regional, de gênero e de orientação sexual" (BRASIL, 2012, p. 1, grifos nossos). O ato de retirar e não aprovar os termos "gênero" e "orientação sexual" do PNE fez com que o mesmo acontecesse em documentos elaborados a posteriori como, por exemplo, o Plano Distrital de Educação (PDE), os Planos Estaduais de Educação (PEE) e os Planos Municipais de Educação (PME) (OLIVEIRA, 2017).

Vale destacar, ainda, que esses movimentos conservadores têm sido crescentes em nosso país, a partir de grupos de posicionamento político de direita, grupos esses interligados aos movimentos neoliberais e neoconservadores (a exemplo Movimento Escola Sem Partido”, “Movimento Pró-Vida e Pró-Família”, , "Cristãos contra a ideologia de Gênero"), que defendem ações contrárias às pautas progressistas, com discursos, principalmente, moralistas, religiosos e retrógrados. Esses grupos defendem, dentre outras ideias, a proibição de temáticas relacionadas a gênero, diversidade sexual, violência nas ações pedagógicas escolares, além de advogar que as instituições escolares não devem discutir sobre machismo, sexismo, misoginia e temas correlatos, enfatizando que esses temas devem ficar a cargo das famílias (BARROCO, 2011).

Esse movimento neoconservador que chegou ao Brasil, de acordo com Apple (1999), surgiu logo após a Segunda Guerra Mundial (1939-1945), mais especificamente por volta de 1960 e 1970. O termo neoconservador começou a ser utilizado principalmente nos escritos europeus e estadunidenses, sendo relegada a sua composição à Nova Direita. E são esses grupos que têm, a todo custo, distorcido os estudos de gênero, alegando que as características ligadas a gênero e à sexualidade devem ser estudadas apenas no campo biológico, desconsiderando aspectos sociais, culturais, políticos, históricos; além disso, 
discorrem que homens e mulheres devem ser - sempre - considerados/as diferentes, por conta da anatomia corporal. Portanto, vamos desmistificar - mesmo que brevemente esse conceito que causa tanto 'medo' socialmente.

Destacamos que as questões de gênero são práticas discursivas contínuas, estando sempre abertas às "[...] intervenções e ressignificações". Mesmo quando o conceito gênero se cristaliza, esta cristalização "[...] é uma prática insistente e insidiosa, sustentada e regulada por vários meios sociais" (BUTLER, 2015, p. 69). Dessa forma, a categoria gênero é algo mutável, está em constante transformação, sendo (re)construída socialmente.

Meyer (2010, p. 16) explica que "[...] o conceito de gênero passa a englobar todas as formas de construção social, cultural e linguística implicadas com os processos que diferenciam mulheres e homens". Essa construção social, portanto, é realizada de acordo com o momento histórico e o ambiente, podendo ser conduzida de formas diferentes em lugares distintos. Por exemplo, ser mulher no Oriente não tem a mesma conotação de ser mulher no Ocidente. Também como exemplo, valem os estudos de Jaqueline de Jesus (2012, p. 08), quando destaca que “[...] ser masculino ou feminino, homem ou mulher, é uma questão de gênero. Logo, o conceito básico para entendermos homens e mulheres é o de gênero". Um conceito amplo, científico, político e que precisa ser, cada vez mais, estudado com rigor teórico e metodológico.

Para compreender esse cenário, incorporamos que as questões relacionadas a gênero não são biológicas, mas sociais, culturais, políticas, econômicas e históricas. "E o gênero vai além do sexo: o que importa, na definição do que é ser homem ou mulher, não são os cromossomos ou a conformação genital, mas a autopercepção e a forma como a pessoa se expressa socialmente" (JESUS, 2012, p. 08).

Guacira Lopes Louro sobreleva que “[...] as muitas formas de fazer-se mulher ou homem, as várias possibilidades de viver prazeres e desejos corporais são sempre sugeridas, anunciadas, promovidas socialmente". Logo, compreender as questões ligadas a gênero exige uma compreensão do ponto de vista dos aspectos social, cultural, político, histórico. De modo que "[...] a inscrição dos gêneros - feminino ou masculino - nos corpos é feita, sempre, no contexto de uma determinada cultura e, portanto, com as marcas dessa cultura" (LOURO, 2001, p. 09-11).

Outro conceito fundamental para a discussão acerca do termo gênero, é a respeito das relações de poder. Isso porque a construção e a desconstrução de gênero são, sempre, compostas e definidas pelas relações sociais, sendo que tais identidades são "[...] moldadas pelas redes de poder de uma sociedade" (LOURO, 2001, p. 11).

Avultamos o conceito de identidade de gênero, que se torna basilar para avançarmos. Lembramos que "[...] é importante destacar que, em termos de gênero, todos os seres humanos podem ser enquadrados (com todas as limitações comuns a qualquer classificação) como transgênero ou "cisgênero"”" (JESUS, 2012, p. 10). Abaixo, organizamos um quadro expondo as duas principais identidades de gênero mencionadas: 


\section{Quadro 1 - Alguns conceitos sobre: gênero, sexualidade, identidade de gênero, cisgênero, transgênero e sexo.}

\begin{tabular}{|c|c|}
\hline NOME & DEFINIÇÃO \\
\hline GÊNERO & $\begin{array}{l}\text { Envolve todas as formas de construção social, cultural e } \\
\text { linguística implicadas com os processos que diferenciam } \\
\text { mulheres e homens. Esse conceito tem o objetivo de distinguir as } \\
\text { diferenças sociais e culturais do homem e da mulher, de modo a } \\
\text { enfatizar as suas características. }\end{array}$ \\
\hline SEXUALIDADE & $\begin{array}{l}\text { Se expressa no estilo de vida que cada pessoa adota, no } \\
\text { modo como se demonstram os afetos, na percepção erotizada } \\
\text { dos estímulos sensoriais e também nos papéis de gênero. A } \\
\text { sexualidade envolve, além do corpo, os sentimentos, a história } \\
\text { de vida, os costumes, as relações afetivas e a cultura. Portanto, } \\
\text { é uma dimensão fundamental de todas as etapas da vida de } \\
\text { homens e mulheres, presente desde o nascimento até a morte, e } \\
\text { abarca aspectos físicos, psicoemocionais e socioculturais. }\end{array}$ \\
\hline IDENTIDADE DE GÊNERO & $\begin{array}{l}\text { É o jeito adotado para vivenciar o feminino ou para vivenciar } \\
\text { o masculino (ou ambos, ou nenhum), que tem implicações nas } \\
\text { relações estabelecidas entre homens e mulheres. A identidade } \\
\text { de gênero é formada constantemente, diariamente, no decorrer } \\
\text { da vida de uma pessoa. Essa identidade pode ser modificada, } \\
\text { porém, ninguém pode obrigar uma pessoa a fazê-lo. }\end{array}$ \\
\hline CISGÊNERO & $\begin{array}{l}\text { Se refere ao indivíduo que se identifica, em todos os aspectos, } \\
\text { com o seu gênero atribuído no momento do seu nascimento } \\
\text { (quando baseado no sexo). }\end{array}$ \\
\hline TRANSGÊNERO & $\begin{array}{l}\text { Se refere ao indivíduo que se identifica com um gênero diferente } \\
\text { daquele que corresponde ao seu gênero atribuído no momento } \\
\text { do nascimento (quando baseado no sexo). }\end{array}$ \\
\hline SEXO & $\begin{array}{l}\text { É a caracterização fisiológica que diferencia macho e fêmea: } \\
\text { composto por, principalmente, um conjunto de hormônios e } \\
\text { aparelho reprodutor (pênis nos machos e vulva nas fêmeas). } \\
\text { Além disso, o sexo pode ser entendido como o coito, ou seja, } \\
\text { a relação sexual praticada entre as pessoas. É um conjunto de } \\
\text { características genotípicas e biológicas. }\end{array}$ \\
\hline
\end{tabular}

Fonte: Elaborado pelos autores e pela autora (2020).

Dessa explicação, ainda valem os estudos de Jesus (2012, p. 10), quando expõe que

há quem se considere transgênero, como uma categoria à parte das pessoas travestis e transexuais. Existem ainda as pessoas que não se identificam com qualquer gênero, não há consenso quanto a como denominá-las. Alguns utilizam o termo queer, outros, a antiga denominação "andrógino", ou reutilizam a palavra transgênero.

Porém, mesmo não havendo um consenso, optamos por dividir a identidade de gênero entre cisgênero e transgênero. Essa divisão não serve para rotular as pessoas, 
mas para mostrar que há diferenciações entre elas e que, independente da identidade de gênero, não há forma 'errada' de vivenciá-lo, devendo todas essas formas ser respeitadas.

Ainda cabe destacar que o Brasil é uma sociedade machista, misógina e sexista, em que inferioriza o valor da mulher em detrimento do poder masculino, de modo que a violência de gênero é uma constante em nosso país. Os movimentos feministas têm impetrado - no Brasil e fora dele - a luta, dentre outras pautas, contra a violência deferida à mulher. Lourdes Bandeira (2014, p. 450) informa que esse tipo de violência "[...] não se refere a atitudes e pensamentos de aniquilação do outro, que venha a ser uma pessoa considerada igual ou que é vista nas mesmas condições de existência e valor que o seu perpetrador", mas "[...] tal violência ocorre motivada pelas expressões de desigualdades baseadas na condição de sexo, a qual começa no universo familiar, onde as relações de gênero se constituem no protótipo de relações hierárquicas". Junto a isso, a autora assevera que "[...] em outras situações, quem subjuga e quem é subjugado pode receber marcas de raça, idade, classe, dentre outras, modificando sua posição em relação àquela do núcleo familiar.

Portanto, é basilar incentivar discussões de gênero e diversidade sexual nas instituições escolares, de modo a contribuir para a diminuição das desigualdades e discriminações sociais, sobretudo às relacionadas às mulheres e pessoas LGBTQIA (lésbicas, gays, bissexuais, travestis, transexuais, transgêneros, queers, questionadoras, bigêneros, assexuadas e intersexos). Essa discussão, se acompanhada de práticas democráticas e científicas escolares, pode contribuir na diminuição da violência reportada a esse grupo em todos os ambientes sociais. Essas ações podem amortecer a misoginia, o machismo, o sexismo, o patriarcado, a LGBTQIAfobia, promovendo a equidade de gênero e diversidade sexual, a partir do exercício do convívio com as diversas características humanas, sociais, políticas, históricas, culturais.

Feitas essas primeiras análises, a seguir discutimos acerca de alguns documentos oficiais brasileiros, traçando perspectivas no intuito de examinar se há menção/discussão de gênero em sua composição.

\section{Documentos oficias: há discussão de gênero?}

Ao pontuar nossa definição sobre gênero nos debruçamos agora a apontar alguns motivos que impedem que essas discussões possam avançar no contexto educativo. Iniciamos com algumas indagações: por que a obsessão da política sobre gênero e sexualidade? Por que investigar sobre gênero/sexualidade no espaço escolar? E por que gênero e sexualidade estão sempre no estado de contestação, de politização e de renegociação?

Altmann (2001, p. 576) contribui com algumas questões sobre o cerceamento das temáticas de gênero e sexualidade no espaço escolar, ao apresentar que esses temas são 
“[...] o que há de mais íntimo nos indivíduos e aquilo que os reúne globalmente como espécie humana"e ainda enfatiza que são temas de interesse público, "[...] pois a conduta sexual da população diz respeito à saúde pública, [...] à força de uma sociedade”.

Para responder a estas questões, destacamos alguns documentos elaborados em nível nacional, que foram feitos com possibilidades de discussões sobre gênero e sexualidade nos espaços escolares, sendo que destacamos somente dois neste contexto, sendo os Parâmetros Curriculares Nacionais (PCN) (BRASIL, 1997) e o Programa Brasil sem Homofobia (BRASIL, 2004). Ao apresentar estes dois documentos, enfatizamos que foram produzidos em conjunto com a sociedade civil comprometida com os estudos de gênero, sendo materiais didáticos possíveis de serem trabalhados nas escolas.

Há muitos materiais e esforços sobre a inserção dessa temática nas escolas, desde o início do século XX (MAIO, 2013), porém atentaremos neste ensaio a partir de documentos do final deste século, em que os materiais foram elaborados, principalmente, pelo Ministério dos Direitos Humanos (MDH) e pelo Ministério da Educação (MEC). Porém, antes, trazemos um breve histórico de tentativas de constituir a educação sexual escolar, como propostas governamentais.

Camila Aquino e Andréa Martelli (2012), apresentam um breve histórico sobre alguns documentos, propostas e ações nacionais, que possibilitaram a inserção da temática de educação sexual nas escolas. Iniciam, com os anos

20 e 30 do século XX a educação sexual fomenta discussões entre médicos, professoras, professores e entre outros profissionais. Nesse período a abordagem predominante caracterizava-se por traços higienistas e eugenistas junto às crianças, adolescentes e jovens, com o intuito de combater as doenças venéreas e preparar os sujeitos para um futuro mais saudável e responsável (s/p).

Um pouco antes da década de 60, a Igreja Católica possuía o domínio do sistema educacional, o que resultou em severa repressão à educação sexual neste período. Pouco se podia ensinar sobre educação sexual escolar, e o que se comentava era sobre materiais de higiene e alguns sobre aparelhos reprodutores (GUIMARÃES, 1995).

Já o Golpe Militar de 1964 ocasionou mudanças políticas radicais que marcaram o território nacional brasileiro. Dentre as mudanças,

\footnotetext{
citamos especificamente a defesa de uma moral por intermédio de um sistema repressor, dessa forma as tentativas anteriores direcionadas à educação sexual foram banidas das escolas. O Brasil passava por renovações pedagógicas, e grande parte dessas iniciativas foi abortada em função da ideologia moralista defendida pelo golpe militar. Embora fossem criadas propostas de renovação pedagógica com discursos voltados a prática da educação sexual, as mesmas eram negadas. Nos anos 1960 foram publicados os livros do padre Charboneau. Escritos numa linguagem filosófica, abordavam a sexualidade baseada na moral cristã, objetivando a consolidação de princípios morais defendidos pela Igreja e a educação para a paternidade (AQUINO, MARTELLI, 2012, s/p).
} 
Ainda em 1968, a deputada Júlia Steimbruck, do Rio de Janeiro, apresentou um projeto de lei à Câmara dos Deputados propondo a implantação obrigatória da educação sexual em todas as escolas do País e em todos os níveis, Não houve adesão de outros partidos, bem como recebeu muitas objeções, principalmente de políticos/as ligados/as à Igreja Católica (GUIMARÃES, 1995).

Os retrocessos ainda continuaram, ainda mais nas escolas, ao se tratar de educação sexual, porém entre 1978 e 1979, foram realizados alguns congressos sobre educação sexual nas escolas de iniciativa privada, em São Paulo e Rio de Janeiro (AQUINO, MARTELLI, 2012). E assim, o interesse dos/as profissionais da educação começou a se manifestar. Vários estudos e discussões foram feitos sobre a necessidade de se ter materiais sobre educação sexual aplicada à instituição escolar (MAIO, 2013).

Em 1997, o Ministério da Educação lançou os PCN, que são diretrizes elaboradas pelo Governo Federal com a finalidade de orientar a educação no Brasil. Foram separados por disciplinas, com a intenção de servir como norteadores para professores/as, coordenadores/as e diretores/as, que podem adaptá-los às peculiaridades locais. O seu 10ํVㅡo Volume é intitulado como Pluralidade Cultural e Orientação Sexual (BRASIL, 1997).

O objetivo do documento era promover discussões com os/as profissionais da educação, assim como pais/mães ou responsáveis, visando a sistematizar as medidas pedagógicas no trato das questões da sexualidade. A intenção primária era descentralizar a temática, em vários campos disciplinares de estudos, sobre itens ligados à saúde sexual, afetividade e sexualidade (BRASIL, 1997).

Na primeira parte, o material apresenta discussões sobre as diversas heranças culturais que convivem na população brasileira, oferecendo informações que contribuam para a formação de novas mentalidades, voltadas para a superação de todas as formas de discriminação e exclusão. Na segunda parte, é visada à promoção da saúde das crianças e dos/as adolescentes, possibilitando trabalhos de ações preventivas às Doenças Sexualmente Transmissíveis/AIDS de forma mais eficaz, bem como discussões sobre gravidez na adolescência. Os temas são mais ligados à saúde reprodutiva e infecções (BRASIL, 1997).

Já, em 2004, a Secretaria Especial de Direitos Humanos lança o Programa Brasil sem Homofobia (BSH) - Programa de Combate à Violência e à Discriminação contra pessoas LGBT e de Promoção à Cidadania de Homossexuais, o que ficou intitulado pejorativamente como "Kit Gay". Este Programa possui o intuito de "[...] promover a cidadania e direitos humanos às [pessoas] lésbicas, gays, bissexuais, travestis [transexuais, transgêneros, queers, questionadores, bigêneros, assexuados e intersexos] a partir da equiparação de direitos e do combate à violência e à discriminação homofóbicas" (BRANDÃO; SANTANA, 2011, p. 167).

O BSH (BRASIL, 2004, p. 11) pautou-se em ações como: 
[...] apoio a projetos de fortalecimento de instituições públicas e não governamentais que atuam na promoção da cidadania homossexual e/ou no combate à homofobia; Capacitação de profissionais [...]; Disseminação de informações sobre direitos, de promoção da autoestima homossexual e; Incentivo à denúncia de violações dos direitos humanos do segmento [LGBTQIA]

Desenvolvido em um trabalho conjunto com indivíduos governamentais e não governamentais, o BSH procurou integrar as diversas esferas sociais no combate à LGBTQIAfobia por meio da articulação da política de promoção dos direitos de homossexuais; legislação e justiça; cooperação internacional; direito à segurança por meio do combate à violência e à impunidade; direito à educação, ao promover valores de respeito à paz e à não discriminação por orientação sexual; direito à saúde e consolidação de um atendimento e tratamentos igualitários; direito ao trabalho; direito à cultura e construção de uma política de cultura de paz e valores de promoção da diversidade humana, entre outros (OLIVEIRA JR; MAIO, 2015).

Desenvolvido ao longo de dois anos, o Kit de Combate à Homofobia seria composto por um conjunto de materiais didáticos incluindo: 06 Boleshs (Boletins Escola sem Homofobia), 01 Caderno (Escola Sem Homofobia) e os Recursos Audiovisuais: Medo de Quê? Boneca na Mochila além de 03 vídeos: Torpedo, Encontrando Bianca e Probabilidade. Esses materiais seriam destinados aos/às profissionais da educação e distribuídos para seis mil escolas públicas de ensino médio, a partir do segundo semestre de 2011. Para a preparação do Kit de Combate à Homofobia foi demandada a confecção de vídeos e cartilhas para professores/as, pesquisas, seminários e atividades de formação para docentes (BALESTERO, 2011).

Este material foi estruturado para ser uma importante ferramenta em que os/as professores/as encontrariam referências teóricas, conceitos e sugestões de atividades e oficinas para discutir com os/as alunos/as a diversidade sexual e combater a LGBTQIAfobia.

Investigações acerca do Kit de Combate à Homofobia do MEC e o furor fundamentalista que o mesmo causou em parte da sociedade e bancadas evangélicas são necessárias, pois, tal lacuna dificulta a adoção de uma visão positiva sobre o/a outro/a, que passa a ser percebido/a como 'diferente', 'desigual', 'inferior' ou 'anormal', quando não segue o padrão heteronormativo imposto nas relações de poder que sustentam as identidades e (re)produzem as diferenças (OLIVEIRA JR; MAIO, 2015).

Parlamentares e bancadas de forte influência religiosa passaram a desqualificar publicamente o material, que foi chamado de "kit gay", porque supostamente objetivava estimular e fazer propaganda do "homossexualismo". Contra a adoção do material, foi realizada uma forte campanha negativa e desonesta, em que informações equivocadas foram divulgadas como verdadeiras. Materiais que não faziam parte do kit, como panfletos de programas de prevenção de riscos de 
DST dirigidos a profissionais do sexo, foram usados de forma falaciosa pelos críticos para angariar repúdio popular contra o Escola sem Homofobia. Deputados assumidamente homofóbicos, como Jair Bolsonaro, chegaram a afirmar que o material buscava "ensinar a ser gay" e seria indiscriminadamente distribuído entre estudantes de 6 a 10 anos. Essas declarações pejorativas tinham a finalidade de criar pânico moral e alarmismo em torno do material, sugerindo-se, de modo distorcido e falso, que a partir dele a pedofilia passaria a ser legalizada e incentivada, por exemplo. Uma significativa pressão pública e moralista foi feita para que o Escola Sem Homofobia fosse abandonado (LOPES, 2016, p. 64).

Diante de toda essa pressão, a presidenta Dilma Rousseff (PT), em seu período de mandato entre 2011 e 2016, concordou que o material visual não possuía teor 'correto' para ser apresentado a crianças e jovens e que o material fazia propaganda de "opção sexual", mesmo não tendo conhecimento do conteúdo do material afirmado. Para a então presidenta do Brasil, a função do Governo é apenas educar para que se evitem agressões e desrespeitos à diferença, não podendo interferir na vida particular dos sujeitos e nem propagar as orientações sexuais (OLIVEIRA JR; MAIO, 2015).

Ora, se todo o estardalhaço sobre a veiculação do Kit de Combate à Homofobia era pelo seu conteúdo impróprio e apologia à homossexualidade como alegavam esses grupos políticos e sociais conservadores, a análise da sua substância mostra um conteúdo simplista e necessário sobre a diversidade sexual na escola, evidenciando ainda mais o caráter homofóbico presente no diálogo de legisladores/as e civis do País.

Buscando exemplificar, este furor causado pelos/as legisladores/as, alguns/mas religiosos/as, tem-se que

o material buscava "ensinar a ser gay" e seria indiscriminadamente distribuído entre estudantes de 6 a 10 anos. Essas declarações pejorativas tinham a finalidade de criar pânico moral e alarmismo em torno do material, sugerindo-se, de modo distorcido e falso, que a partir dele a pedofilia passaria a ser legalizada e incentivada (LOPES, 2016, p. 64).

Assim, analisando os dois materiais aqui propostos, os PCN (BRASIL, 1997) e o Programa Escola sem Homofobia (BRASIL, 2004), afirmamos que há materiais que possam ser trabalhados nos espaços escolares - mesmo quando esse último não fora distribuído para as instituições escolares - visando a protagonizar discussões sobre gênero e sexualidade, possibilitando que os/as discentes compreendam sobre essa temática visando a minimizar ou então acabar com preconceitos, interditos e mazelas que por ventura ainda ocorram. 


\section{Práticas escolares envolvendo gênero}

Os discursos que se desencadeiam, hoje, dos gabinetes do Poder Executivo como da Presidência da República, do Ministério da Educação (MEC) e Ministério da Mulher, da Família e Direitos Humanos (MDH) desqualificam estudos e pesquisas realizados ao longo das últimas décadas nos espaços acadêmicos nacionais e internacionais, pois atribuem centralidade à família nuclear e retiram de pauta muitos direitos que foram legislados em defesa de minorias, como, por exemplo, as mulheres e as pessoas LGBTQIA.

Ao nosso ver, a negação de direitos nas esferas políticas da atualidade é produzida a partir de narrativas que emanam do Poder Executivo, por diversas vias: o gabinete do ódio, criado no interior da Palácio do Planalto cuja finalidade é promover ataques a diversos grupos sociais e políticas já em andamento por meio de fake news; campanhas de abstinência sexual propagadas nas diferentes mídias; a proliferação de ideias desencontradas, como no caso do Programa Brasil sem Homofobia, também conhecido como "kit gay", o qual, no discurso direitista e homofóbico, compila, ainda hoje, a distribuição de materiais de educação sexual para a formação da identidade homossexual, inclusive, incluía "mamadeiras de pirocas" para crianças da educação infantil. Tais discursos são em favor da família, da religião e da "moral" social.

Embora o Projeto de Lei da Câmara 122 de 2006, (PLC 122/2006) ou PL 122, também conhecida como lei anti-homofobia, (BRASIL, 2006) tenha sido vetado pela então presidenta Dilma Rousseff em 2011, o Projeto "Escola sem homofobia", lançado em 2004 foi financiado pelo Ministério da Educação através de recursos aprovados no Congresso, por Emenda Parlamentar da Comissão de Legislação Participativa (BRASIL, 2004). Tal projeto, ainda que não tenha se transformado em uma política de Estado, pode ser considerado como um marco histórico para a promoção de uma educação mais justa e igualitária, tanto no reconhecimento das diferentes identidades, quanto da sua valorização.

A tentativa de impor regras escolares que convergem com um modelo único de sujeito heterossexual pode ser vista na apresentação do Projeto de Lei nº 7180/2014 (BRASIL, 2014b), proposta pelo deputado Erivelto Santana (PSC-BA), que inclui, entre as Diretrizes e Bases da Educação Nacional, o Programa Escola sem Partido (BRASIL, 2014b). Dada a força que o projeto ganhou, principalmente nos meios religiosos, foram apensas ao projeto inicial outras duas propostas, as PL 867/2015 e 246/2019.

No bojo das lutas pelos direitos individuais e coletivos no Brasil, outro projeto foi apresentado no Congresso Nacional em 2019, PL 502/2019 (BRASIL, 2019), que institui o Programa "Escola Sem Mordaça” de autoria das deputadas Talíria Petrone (PSOL-RJ), Luiza Erundina (PSOL-SP), Fernanda Melchionna (PSOL-RS), dentre outros/as. Tal proposição é uma resposta dos/as idealizadores/as de uma escola que tenha voz e seja respeitada na sua autonomia, conforme determina a LDBEN (BRASIL, 1996). 
Ao considerarmos o cenário de lutas ideológicas conservadoras, principalmente, que assombram os espaços políticos e sociais na atualidade, somos defensores/as de uma escola que seja emancipadora e conscientizadora, que não limite o gênero e a sexualidade apenas aos fatores biológicos/genéticos, mas sim na sua diversidade, uma vez que é fundamental que as crianças e os/as jovens [...] desenvolvam a consciência crítica e compreendam os sistemas e as formas dominantes de representação da identidade e da diferença" (ARAÚJO, CRUZ, DANTAS, 2018, p. 31).

A negação dos aspectos de gênero e sexualidades no currículo escolar, de acordo com Furlani (2007, p. 275), pode ser vista como “[...] os monstros, assim como figuras folclóricas, originam-se de um entendimento metafórico de algum momento social, de alguma passagem cultural, sendo, portanto, específicos de contextos históricos e locais". Isso justificaria os discursos políticos que se acentuam na atualidade como fator de hierarquização de ideologias, religiosas ou de classes, como o Projeto de Lei "Escola Sem Partido" (BRASIL, 2014b) ou a campanha da "Abstinência sexual" (CNS, 2020).

Ao inserir no currículo escolar as temáticas sobre gênero e sexualidades, os/as docentes podem propor uma série de atividades, nas diferentes áreas, que contemplem as relações afetivas, sexuais, de poder, de classe, sempre respeitando os pontos de vista, as religiosidades e cultura de cada estudante, dentre as quais destacamos algumas a partir de agora.

Muitas obras literárias brasileiras, principalmente após o período do Romantismo Nacional, abordam as questões de gênero, as relações de poder entre eles, os papéis sociais que foram se estabelecendo ao longo dos tempos, por isso, os escritos literários podem oferecer subsídios pedagógicos, pois apresentam além de contextos, diferentes identidades, desde os clássicos infantis até os clássicos nacionais.

Por exemplo, as literaturas infantis vêm apresentando uma nova roupagem. Em "Príncipe Cinderelo" (Babette COLE, 2011), é possível que o/a professor/a chame a atenção para os papéis que tradicionalmente foram atribuídos aos príncipes e às princesas, mostrando que ambos/as são seres humanos, portanto, o lugar que cada um/a ocupa diz respeito à sua realidade social. Nesse caso o príncipe é feio, magro e baixo, anda de ônibus e é pedido em namoro pela princesa que valoriza as suas atitudes e não sua imagem social. Assim, é perceptível a quebra de estereótipos.

Na obra "Menino brinca de boneca?" (RIBEIRO, 2011), a narrativa apresenta atividades diárias e sentimentos que são alheios a meninos e meninas e demonstram que ninguém é igual a ninguém, cada um/a tem seu jeito de ser, sua forma de se vestir e habilidades para determinadas coisas, por isso, quando bem contada, a história permite à criança perceber que a humanidade é uma ampla diversidade que precisa ser respeitada em prol de uma boa convivência.

Tanto a narrativa "Príncipe Cinderelo" (COLE, 2011), quanto "Menino brinca de boneca?" (RIBEIRO, 2011) dão espaço para uma infinidade de atividades pedagógicas 
como: criação de histórias em quadrinhos, ilustrações, pesquisas sobre a participação de meninos/as no esporte, diálogos sobre a maternidade/paternidade, narrativas sobre a participação de meninos/as nas atividades de casa etc. Dessa forma, acreditamos que os espaços sociais de convivência desses/as futuros/as jovens tendem a ser mais justos e menos excludentes - homens e mulheres poderão ser tratados/as com igualdade e, papéis sociais hierarquizados possam ser desconstruídos.

No romance "Senhora" publicado pela primeira vez em 1875 (ALENCAR, 1875), a trama se dá em torno de Aurélia Camargo, uma moça pobre que se apaixona por um rapaz que, mesmo a amando, assume compromisso com outra mulher devido ao dote, uma espécie de liquidação paga ao pretendente pela família da mulher. Ao receber uma herança, Aurélia compra o ex-pretendente e deixa de cumprir suas 'funções' de esposa, pois para ela, ele não a amava. A trama se resolve quando Fernando Seixas devolve o dote, como prova do seu amor. As relações de gênero que são fortemente apresentadas no texto marcam a alta sociedade carioca do século XIX, em que ser mulher e ser homem possuíam papéis distintos. O homem deveria ser cavalheiro, possessivo, forte e opressor, enquanto a mulher, além de pagar por um marido, deveria obediência e submissão a ele.

Além da literatura cumprir com a sua função artística literária, pode corroborar para reflexões acerca do papel que os diversos sujeitos sociais ocuparam e ocupam ao longo dos tempos (Florentina SOUZA, 2008), evidenciando que falar de identidades e modos de vida se tratam de questões construídas histórica e culturalmente, portanto a manutenção das diferenças entre os sujeitos sociais e históricos depende de cada um/a de nós.

A arte é uma área interdisciplinar que acompanha a história, por isso ela pode ser utilizada para trabalhar aspectos geográficos, sociais, naturais, artísticos, linguísticos etc. no campo da escultura, há a presença de uma infinidade de obras que retratam crenças, mitos, sentimentos e emoções. Datada entre 28.000 a 25.000 a.C., a estatueta rupestre Vênus de Willendorf retrata a figura de uma mulher da época, de seios, ancas e púbis fartas, baixa e gorda, quase sem pescoço, o que revela que os padrões de beleza da época valorizavam a fertilidade e a maternidade em detrimento dos aspectos corporais (PROENÇA, 1994). Além de abordar o caráter histórico da Arte, a obra também contempla os estudos na área da disciplina de História e Geografia, no que diz respeito ao lugar de produção e os modos de vida da época.

Outro exemplo de material pedagógico são os filmes, isso porque ver filmes, discuti-los, interpretá-los é uma via para ultrapassar as nossas arraigadas posturas etnocêntricas e avaliações preconceituosas, construindo um conhecimento descentrado e escapando às posturas "naturalizantes" do senso comum (TEIXEIRA; LOPES, 2006).

Tanto longas quanto curtas metragens oferecem boas opções de trabalho em sala de aula. Um exemplo é o curta-metragem "Eu não quero voltar sozinho" de 2010 e o longa-metragem brasileiro "Hoje quero voltar sozinho" de 2014, ambos dirigidos, produzidos e roteirizados por Daniel Ribeiro (2010; 2014). As narrativas contam a história 
de dois amigos e uma relação que surge na escola entre Leo (cego) e Gabriel; com isso, é possível mostrar aos/às adolescentes que a afetividade, o amor e a sexualidade estão entre todos os grupos de convivência social, inclusive entre os/as adolescentes, que não se trata de escolhas, mas sim de sentimentos que surgem independentemente da idade, da classe social ou de qualquer outra condição humana.

Para Araújo, Cruz e Dantas (2018), nas aulas de ciências/biologia, além de trabalhar os conteúdos comumente discutidos (assuntos estritamente biológicos), podem-se também abrir espaço para as discussões acerca dos corpos sexualizados, seus espaços de vivência, as transformações que vão ocorrendo ao longo da nossa vida, como também aquelas que sentimos necessidades em procedê-las como a redesignação sexual, por exemplo, evidenciando sempre que além de um caráter biologicizado, o corpo é resultado de vivências, transformações socioculturais, prazer sexual e sentimentos afetivos.

A escola não pode estreitar as temáticas sobre a sexualidade somente na dimensão biológica/genética, é preciso preceituar gênero e sexualidades como algo inerente aos seres humanos (BRASIL, 1997) e, portanto, precisam ser compreendidas, evitando assim práticas repressoras que ditam papéis. A sexualidade precisa ser vista de forma despreconceituosa e vivenciada com responsabilidade, tanto para a emancipação individual, quanto do grupo, e para uma melhor harmonia entre a diversidade.

Para respaldar o trabalho que os/as docentes realizam acerca das temáticas sobre gênero e sexualidades nas escolas, muitos documentos foram construídos e aprovados, os quais refletem em Diretrizes, Resoluções, Pareceres, à própria Constituição Federal de 1988 (BRASIL, 1988) e à LDBEN 9394/96 (BRASIL, 1996) quando apregoam à educação a liberdade de ensinar e aprender, o respeito à cultura, ao pensamento e aos saberes extraescolares. Por isso, ao planejar sua aula ou suas atividades e projetos escolares, os/ as professores podem fazê-lo de forma fundamentada nos princípios educativos que fazem parte de um arsenal político educacional. A impossibilidade disso, se condicionaria a negar os princípios de uma educação universal, democrática e para todos/as.

\section{Considerações finais}

A partir dos estudos realizados, fica evidente que, geralmente, quem está no poder (ou exerce esse poder) dita as normas 'aceitas' e 'não aceitas' a respeito da categoria gênero. Aqui, rebuscamos a discussão feita anteriormente dos grupos neoconservadores: esses grupos buscam, a toda medida, impor maneiras de pensar, discutir e vivenciar a categoria gênero. Sempre ao seu modo excludente, estático, impositivo.

Vale lembrar que em uma sociedade como a brasileira, constituída e estruturada na diversidade, em que as diferenças são, com frequência, produzidas no curso das relações 
assimétricas, a promoção da cultura do reconhecimento da diversidade sexual e de gênero pode representar mais do que um compromisso ético: um direito irrenunciável.

De acordo com os PCN (BRASIL, 1997, p. 83), cabe à escola abordar os “[...] diferentes pontos de vistas, valores e crenças que circulam na sociedade para auxiliar o aluno [e a aluna] a encontrar um ponto de auto referência por meio da reflexão". Esse posicionamento também é defendido pelos estudiosos/as da área de gênero e diversidade sexual (MEYER, 2010; OLIVEIRA, 2017; MAIO, 2013)

Por isso, a compreensão que os/as professores/as possuem sobre a diversidade de gênero e sexual pode suscitar discursos, práticas pedagógicas e até projetos educativos que emancipem os/as alunos/as. Por meio da aprendizagem dos conteúdos escolares, os/as jovens podem entender seus conflitos, seus desejos, seus limites, assim como os de seus pares, o que poderia diminuir violências, e proporcionar mais respeito nas suas vivências em grupos diversos; no entanto, muitas vezes, a escola se retrai e ignora a diversidade para silenciar, como se não existissem implicações em determinados silêncios (ARAÚJO, CRUZ, DANTAS, 2018).

Assim, discutir, estudar sobre gênero, sexualidades e diversidades, não tem sido uma tarefa muito fácil, quando o espaço dessa discussão é o escolar, principalmente nos últimos anos, quando o conservadorismo tem imperado e as ideologias religiosas têm sido levantadas em favor da família nuclear, da heterossexualidade e da abstinência sexual de jovens estudantes. O papel da escola deve ser diariamente fundamentado nas experiências humanas, portanto, científico, social e menos excludente. Depende dos/as gestores/as políticos/as, escolares, dos/as educadores/as e de toda a comunidade escolar. Em tempos de discursos políticos religiosos sombrios é difícil, mas não é impossível.

Recebido em: 29/04/2020 e Aprovado em: 05/06/2020

\section{Referências}

ALENCAR, José de. Senhora. 1875. Disponível em <http://www.dominiopublico.gov.br/pesquisa/ DetalheObraForm.do?select_action=\&co_obra=2026>. Acesso em: 24 abr. 2020.

ALTMANN, Helena. Orientação sexual nos parâmetros curriculares nacionais. Rev. Estud. Feministas, Florianópolis, v. 9, n. 2, p. 575-585, 2001.

APPLE, Michael Withman. Conhecimento oficial: a educação democrática numa era conservadora. Tradução de Maria Isabel Edelweiss Bujes. 2. ed. Petrópolis/RJ: Vozes, 1999. 
BALESTERO, Gabriela Soares. O direito à diversidade sexual no Brasil e os efeitos violentos do descaso do poder legislativo federal. Revista Espaço Acadêmico, Maringá, v. 11, n. 123, ago., 2011, p. 05-16.

BANDEIRA, Lourdes Maria. Violência de Gênero: a construção de um campo teórico e de investigação. Revista Soc. e Est., Brasília, v. 29, n. 02, mai./ ago., 2014.

BRANDÃO, Paula de Freitas; SANTANA, Tereza. O "kit gay": na saúde e na educação um kit de polêmicas. Caos - Revista Eletrônica de Ciências Sociais, João Pessoa, n. 18, set. 2011, p. 167-176.

BRANDÃO, Elaine Reis; LOPES, Rebecca Faray Ferreira. "Não é competência do professor ser sexólogo" - o debate público sobre gênero e sexualidade no Plano Nacional de Educação. Civitas, Porto Alegre, v. 18, n. 01, p. 100-123, jan./abr., 2018.

BARROCO, Maria Lúcia S. Barbárie e neoconservadorismo: os desafios do projeto ético-político. Ser. Soc. \& Soc., São Paulo, n. 106, p. 205-218, abr.jun. 2011.

BRASIL. Projeto de Lei da Câmara noo. 103, de 2012. 2012. Disponível em: <https://legis.senado.leg.br/ sdleg-getter/documento?dm=3981690\&ts=1567529073737\&disposition=inline $>$. Acesso em: 21 maio 2020.

BRASIL. Plano Nacional de Educação - Lei nọ. 13.005/2014. Brasília: Presidência da República, 2014a.

BRASIL. Parâmetros Curriculares Nacionais: pluralidade cultural, orientação sexual. Brasília: MEC/SEF, 1997.

BRASIL. Brasil Sem Homofobia: Programa de combate à violência e à discriminação contra LGTB e promoção da cidadania homossexual. Brasília: Ministério da Saúde, 2004.

BRASIL. Projeto de Lei no 7180/2014. Brasília: Câmara Federal, 2014b. Disponível em: <https://www. andes.org.br/diretorios/files/Projeto\%20de\%20Lei\%20Escola\%20Sem\%20Mordaca.pdf $>$. Acesso em: 22 abr. 2020.

BRASIL. Projeto de Lei no 502/2019. Brasília: Câmara Federal, 2019. Disponível em: <https://www. andes.org.br/diretorios/files/Projeto\%20de\%20Lei\%20Escola\%20Sem\%20Mordaca.pdf $>$. Acesso em: 22 abr. 2020.

BRASIL. Lei de Diretrizes e Bases da Educação Nacional. Brasília: Presidência da República, 1996.

BRASIL. CÂMARA FEDERAL. Projeto de Lei da Câmara nº 122/2006. Disponível em: https://www25. senado.leg.br/web/atividade/materias/-/materia/79604. Acesso em: 22 mai. 2020.

BUTLER, Judith. Problemas de Gênero: feminismo e subversão da identidade. 8. ed. Trad.: Renato Aguiar. Rio de Janeiro: Civilização Brasileira, 2015.

CNS. CNS recomenda que governo cancele campanha de abstinência sexual. 2020. Disponível em: <http://conselho.saude.gov.br/ultimas-noticias-cns/1005-cns-recomenda-quegoverno-cancele-campanha-de-abstinencia-sexual>. Acesso em: 23 abr. 2020.

COLE. Babette. Príncipe Cinderelo. São Paulo: Martins Fontes, 2011.

FURLANI, Jimena. Sexos, sexualidades e gêneros: monstruosidades no currículo da Educação Sexual. Educação em Revista. Belo Horizonte, n. 46, dez. 2007, p. 269-285.

GUIMARÃES, Isaura. Educação Sexual na Escola: mito e realidade. Campinas/SP: Mercado de Letras, 1995.

JESUS, Jaqueline Gomes de. Orientações sobre identidade de gênero: conceitos e termos. 2. ed. Brasília, 2012. 
LARROSA, Jorge. Sobre a lição. In: LARROSA, Jorge. Pedagogia Profana: danças, piruetas e mascaradas. 5. ed. Belo Horizonte: Autêntica, 2010, p. 139-146.

LOPES, Laís Godoi. Coleção Cadernos de Direitos Humanos: Cadernos Pedagógicos da Escola de Formação em Direitos Humanos de Minas Gerais. EFDH-MG Direitos Humanos e Cidadania: Proteção, promoção e reparação dos Direitos das Pessoas LGBT e de identidade de gênero V.07. Belo Horizonte: Marginália Comunicação, 2016.

LOURO, Guacira Lopes. Pedagogias da Sexualidade. In: LOURO, G. L. O corpo educado: pedagogias da sexualidade. 2. ed. Belo Horizonte: Autêntica, 2001, p. 07-34.

MAIO, Eliane Rose. História da educação sexual no Brasil: dos ginásios vocacionais à Nova LDB (19601980). Doxa, Araraquara, v.17, n.1 e 2, 2013, p.183-219.

MEYER, Dagmar Estermann. Gênero e educação: teoria e política. In: LOURO, G. L.; FELIPE, J.;

GOELLNER, S. V. (Orgs.). Corpo, Gênero e Sexualidade: um debate contemporâneo na educação. 6. ed. Petrópolis/RJ: Vozes, 2010, p. 09-28.

OLIVEIRA JÚNIOR, Isaías Batista; MAIO, Eliane Rose. Diversidade sexual e homofobia: a cultura do "desagendamento" nas políticas públicas educacionais. Práxis Educativa, Ponta Grossa, v. 10, n. 1, jan./ jun. 2015, p. 35-54.

OLIVEIRA, Márcio de. Políticas públicas e violência sexual contra crianças e adolescentes: Planos Municipais de Educação do Estado do Paraná como documentos de (não) promoção da discussão. 136f. Tese (Doutorado em Educação) - Universidade Estadual de Maringá. Maringá, 2017.

PROENÇA, Graça. História da Arte. São Paulo: Ática, 1994.

RIBEIRO, Daniel. Eu não quero voltar sozinho. 2010. Disponível em: <http://www.adorocinema.com/ filmes/filme-226049/>. Acesso em: 25 abr. 2020.

RIBEIRO, Marcos. Menino Brinca de Boneca? 3. ed. rev. e reform. São Paulo: Moderna, 2011.

RIBEIRO, Daniel. Hoje eu quero voltar sozinho. 2014. Disponível em: <http://www.adorocinema. com/filmes/filme-224664/>. Acesso em: 25 abr. 2020.

TEIXEIRA, Inês Assunção de Castro; LOPES, José de Sousa Miguel. A diversidade cultural vai ao cinema. Belo Horizonte: Autêntica, 2006.

SOUZA, Florentina. Gênero e "raça" na literatura brasileira. Estudos de Literatura Brasileira Contemporânea. Brasília, n. 32, p. 103-112, 2008. 